\title{
Mechanical and Microstructural Characterization of Plasma Welded Joints of 18 Ni-300 Maraging Steels Subjected to Repairs
}

\author{
1,2Paulo Roberto Sakai, ${ }^{1,2}$ Deivid Ferreira da Silva, ${ }^{3,4 *}$ Milton Sérgio Fernandes de Lima, \\ ${ }^{2}$ Rafael Humberto Mota de Siqueira and ${ }^{1,3,4}$ Antonio Jorge Abdalla \\ ${ }^{1}$ Department of Materials, Faculty of Engineering of Guaratinguetá-Paulista State University- "Júlio de Mesquita Filho”, Brazil \\ ${ }^{2}$ Department of Aerospace Science and Technology-DCTA, Aeronautics and Space Institute-IAE, Brazil \\ ${ }^{3}$ Institute for Advanced Studies-IEAv, Department of Aerospace Science and Technology-DCTA, Brazil \\ ${ }^{4}$ Applied Physics and Mathematics, Post-Graduation in Space Sciences and Technologies-PG/CTE, \\ Technological Institute of Aviation, ITA, Brazil
}

Article history

Received: 28-01-2021

Revised: 25-02-2021

Accepted: 06-03-2021

Corresponding Author: Milton Sérgio Fernandes de Lima

Institute for Advanced Studies-IEAv, Department of Aerospace Science and Technology-DCTA, Brazil Email: miltonsflima@gmail.com

\begin{abstract}
Among the ultra-high strength structural steels, 18Ni-300 Maraging steel is one of the most important for the naval and aerospace industries. For example, in the manufacture of motor envelopes Plasma Arc Welding-PAW processes are used with the keyhole technique. The joints are regions of high responsibility and undergo a non-destructive inspection according to the standardized technical criteria. If there is an unacceptable defect, the weld is partially removed and repairs are made to the original weld. The objective of this work is to analyze the weld repairs in $18 \mathrm{Ni}-300$ Maraging steel sheets from a microstructural, corrosion and mechanical behavior point of view. Plasma Arc Weld (PAW) repairs, up to three repairs, were carried out in the same location and the modifications produced in the Fusion Zone (FZ), in the Heat Affected Zone (HAZ) and surroundings were evaluated. Microstructural changes were observed due to thermal cycling, such as: Phase transformations, formation of precipitates and reversed austenite, mainly altering the Heat-Affected Zone (HAZ) and the transition region to the Base Metal (BM). There is a reduction in hardness in this region with a consequent decrease in tensile mechanical properties. The application of aging heat treatment partially restored the microstructure affected by the welding and repairs; however, the fractographic analyzes show that the most vulnerable region remains the FZ and the transition region between it and the HAZ. Despite this effect, the loss in tensile strength is low and the ductility of the material is preserved, indicating the feasibility of using welding by the PAW process and the use of up to three repairs to the structure.
\end{abstract}

Keywords: Maraging 300 Steel, PAW Welding, Repair Welding, Heat Aging Treatment, Mechanical Properties, Microstructural Characterization

\section{Introduction}

The material used to manufacture a rocket motor envelope must have specific functional and technical characteristics with high performance under severe conditions. It also needs to combine excellent mechanical properties, mainly resistance and tenacity, with a low specific mass (Rajan and Narasimhan, 2002). In the case of satellite launchers, for example, the payload reaches less than $5 \%$ of the total weight (Bruhn, 1967), making it essential to reduce the vehicle's mass.

Among the candidate materials for aerospace use are composites and metallic materials. Composite materials (filament-reinforced plastic) have lower density and lower cost, however, metallic materials are more robust, have better ductility, can flow before failure and withstand higher working temperatures (700 to $\left.1000^{\circ} \mathrm{C}\right)$.

Maraging steels can be used in the transport, manufacturing, tools, electromechanical sector and, mainly, for the nuclear and military industry, being one of the most suitable for the aerospace sector (Sun et al., 2020; Reis et al., 2015). These steels are ultra high strength (yield strength above $1380 \mathrm{MPa}$ ), have good corrosion resistance, good creep resistance and heat treatment facility to optimize mechanical properties (Chakravarthi et al., 2017; 
Schmidt and Rohrbach, 1991; AMS 2759/3E, 2008; AMS 6514G, 2010; Vasudevan et al., 1990).

Hall and Slunder (1968) report the use of maraging steel for both small rocket engines with a diameter of $406.4 \mathrm{~mm}$ and walls with $1.78 \mathrm{~mm}$ (HARP Project-High Altitude Research Program) and for large motor envelopes, as tested by NASA, with a diameter of 6604 $\mathrm{mm}$ and thicknesses from 10 to $15 \mathrm{~mm}$. In the Brazilian case, the last satellite launch vehicle designed has one of the propulsion stages, called S43, with a diameter of about $1000 \mathrm{~mm}, 6500 \mathrm{~mm}$ in length, the thickness of the steel walls is about $3.3 \mathrm{~mm}$. These are formed by calendered plates and plasma welded to form the cylinder of the motor envelope. This structure has the specification for a tensile strength limit of $1765 \mathrm{MPa}$ and a hardness of 52 to 55 HRC (Sakai, 2015).

Several studies have been indicating for decades the superiority of two types of steels for rocket application, D6AC and Maraging. These alloys show similarities in the properties of specific strength, fracture toughness, specific stiffness, machinability, cost and coefficient of thermal expansion, however, with advantages for Maraging steel when considering corrosion resistance and stress corrosion (Rajan and Narasimhan, 2002; Poinke and Garland, 1973; Matsuo and Kawaguchi, 1995; Suresh, 2008).

For the aerospace sector, the combination of high strength-to-weight ratio and good fracture toughness of Maraging is essential and proves to be superior when compared to other high-strength steels (ESA, 2004; ASM, 2019). Due to its low carbon content, it presents good weldability and dimensional stability (Galindo-Nava et al., 2016). One of the important factors that increases the hardness and resistance of Maraging $18 \mathrm{Ni}$ steel, without marked loss of ductility, is the aging hardening process. Aging occurrs mainly in the range of 455 to $510^{\circ} \mathrm{C}$, below the reversion temperature for austenite (Reis et al., 2016; Pardal et al., 2006), allowing the uniform precipitation of various intermetallic compounds such as $\mathrm{Ni}_{3} \mathrm{Ti}, \mathrm{Ni}_{3} \mathrm{Mo}$ and $\mathrm{Fe}_{2} \mathrm{Mo}$ (Fanton et al., 2014; Dos Reis et al., 2015).

The welding process is not free from defects, nondestructive analyzes performed by Xrays and dyes must analyze the welded region and eventually, in cases of defects not acceptable by technical standards, the element must be rejected or if possible repaired. However, the repair process involves removing part of the previous weld, with the defect and applying a new weld layer, involving a new thermal cycling and alteration of the region's microstructure (Sakai et al., 2015).

Complex processes are activated when carrying out repairs, as they involve new fusion and solidification with formation of dendritic structure, redistribution of solutes and transformation of phases. The heterogeneities in the chemical composition with the enrichment of elements such as $\mathrm{Ni}, \mathrm{Co}, \mathrm{Mo}$ and $\mathrm{Ti}$, can lead to the formation of retained austenite, with a localized reduction in the properties of steel (Pardal, 2012). There is also the phenomenon of grain growth and austenite reversal, which reduce hardness and mechanical properties. In regions where the temperature reaches values close to $500^{\circ} \mathrm{C}$ there is the precipitation of intermetallic, with a localized increase in the hardness value (Reis et al., 2016). Due to all these phenomena, it is essential to analyze in detail the microstructure and the influence of the thermal cycles of each repair used (Reis et al., 2015; Sakai et al., 2016; de Lima et al., 2019).

Marcisz et al. (2017) studied the influence of temperature and aging time on the mechanical properties of Maraging $18 \mathrm{Ni} 350$ steel, this same aging will also occur due to the thermal cycling of the welding process or welding repairs. Depending on the distance of the microstructure to the fusion zone, a corresponding temperature range will be developed and the localized phenomena depend on the chemical composition and the times and temperatures developed in the region (Blondeau, 2008).

This study was carried out to try to reduce the gap in the literature regarding the effects of welding repairs carried out on aerospace structures. Some works with weld repairs for other types of materials and applications, such as stainless steel, DH36 steel, aluminum alloys and titanium show the technical feasibility of carrying out repairs, provided that respected the peculiarities of the welding process and subsequent heat treatments, however, losses in resistance and ductility properties are generally observed (Teng et al., 2017; Kanne Jr et al., 1999; Reimann et al., 2017; He et al., 2017). Few articles were found for Maraging steel, (Sinha et al., 1993) used the Maraging 250 and performed up to two repairs per weld, finding a loss in mechanical strength of 5 to $6 \%$. Ahmed et al. (2012), using the same steel, observed a $10 \%$ reduction in strength after making two repairs and aging the alloy. In this study, we sought to deepen the understanding of the microstructural processes involved in the repaired region. After welding, up to three repairs were made to the weld bead of Maraging 18Ni steel (300) and the changes in the microstructure and mechanical properties resulting from this interference were analyzed.

\section{Experimental}

\section{Materials}

The material used was Maraging $18 \mathrm{Ni}$ steel (300) produced by BÖHLER in the form of a $3.35 \mathrm{~mm}$ thick plate, which was hot rolled and solubilized (hot rolled, annealed). In the welding process, the MAR300 steel alloy in the form of wire addition material with a diameter of $0.889 \mathrm{~mm}$, according to the AMS 6463D standard (AMS 6463D, 2009). Table 1 shows the chemical composition of Maraging steel sheet and filler metal used in welding and carrying out repairs. 


\section{Welding}

From the sheet received from Maraging 300 steel, pieces $400 \mathrm{~mm}$ long and $100 \mathrm{~mm}$ wide were cut in the transverse direction. The surfaces next to the weld were cleaned with a cloth and acetone to remove contaminations and oxides.

The welding was carried out similarly to what is done for the manufacture of the cylindrical sections of the metallic motor envelopes of the Institute of Aeronautics and Space IAE (Brazil) called longitudinal welding $\left(90^{\circ}\right.$ with the lamination direction). This is the most critical position, because the weld supports the greatest loads during a launch. The process was carried out continuously with filler metal in a single pass and in the flat position. In Fig. 1a some cut sheets are shown and in Fig. 1b the strips prepared to receive plasma welding.

For the welding, PAW was used with the technique called keyhole and butt welding. The welding equipment was used in direct non-pulsing current. The parameters used are shown in Table 2.

\section{Weld Repairs}

After the welds, the repairs were carried out as shown in Fig. 2a, with an length of $80 \mathrm{~mm}$. This is sufficient to machine four specimens according to the (AWS B4.0, 2007) standard. Among the regions that received repairs, a space was left to remove specimens to verify the effect of the heat emanated from the repairs carried out.

The opening in the weld bead for the repair was carried out with an abrasive disc with a thickness of approximately $3 \mathrm{~mm}$ (Fig. 2b). The depth of $2.3 \mathrm{~mm}$ (70\% in depth) was removed leaving $1.0 \mathrm{~mm}$ of the original cord. Subsequently, the channels were prepared with a rotary sander $(60 \mathrm{mesh})$ and cleaned with acetone. The repair was made with the filler metal indicated in Table 1 by GTAW with a current of $50 \mathrm{~A}$ and a flow rate of the shielding gas (argon) of $81 / \mathrm{min}$.

The samples were prepared with one, two or three repairs at these locations (Fig. 2), afterwards, the microstructural changes were analyzed and specimens were made to evaluate the mechanical properties.

\section{Heat Treatment and Mechanical Properties}

From the welded and inspected joint specimens were manufactured for the tensile tests according to the (AWS B4.0, 2007) standard by the wire EDM process. In
Fig. 3a the coupon drawing is shown and in Fig. $3 b$ the specimen cut by EDM, leaving the weld bead in the center of the specimen. Four specimens were tested for each condition studied.

The specimens, without repair and with the repairs, were submitted to the heat treatment of solubilization and aging. Following recommendations from (AMS 6521C, 1991). Solubilization was carried out at a temperature of $815 \pm 5^{\circ} \mathrm{C}$ with a $60 \mathrm{~min}$ stay in the oven in an uncontrolled atmosphere. For the thermal treatment of aging the steel was heated to a temperature of $480 \pm 5^{\circ} \mathrm{C}$ with a period of $3 \mathrm{~h}$ in the oven in an uncontrolled atmosphere. In both processes, the heating rate was $200^{\circ} \mathrm{C} / \mathrm{h}$ and cooling was done in air up to $25^{\circ} \mathrm{C}$.

For the performance of the tensile tests, the servohydraulic traction machine type MTS model $810.23 \mathrm{M}$ with $250 \mathrm{kN}$ of capacity was used with the test speed of 1 $\mathrm{mm} / \mathrm{min}$. At least three coupons were tested for each condition studied.

Vickers Hardness measurements (HV) were also made by micro-indentation on samples of all studied conditions. The equipment used was the FUTURE TECH microhardness model FM-700 with a load of $300 \mathrm{gf}$ and with a penetration time of $15 \mathrm{sec}$. Figure 4 shows a schematic of the measurements taken in two directions: (a) Verticalalong the bead from the root to the top of the weld (line A-A) and (b) horizontal-from the center of the weld bead in towards the Base material (BB line). The space between two consecutive measurements was $0.25 \mathrm{~mm}$.

\section{Microstructural Characterization}

For the microstructural analysis. samples were taken from the welding and repair regions. These were embedded in bakelite, sanded with granulometries up to 800 mesh and then polished with alumina solution (1 $\mu \mathrm{m})$ and with colloidal silica solution $(0.1 \mu \mathrm{m})$. For the exams, the optical microscope model AXIO IMAGER 2 from ZEISS was used.

For microscopic analysis, different reagents were used depending on the purpose of the examination. Table 3 shows the different solutions used.

The geometric measurements of the weld bead were taken from the embedded samples using a Holtermann LH-10/20x magnifying glass and the OPTIV Classic VM 3020 profile projector.

Table 1: Chemical composition of base material and wire welding addition (wt \%)

\begin{tabular}{lllllllllllll}
\hline Elements & $\mathrm{Al}$ & $\mathrm{Ca}$ & $\mathrm{C}$ & $\mathrm{Co}$ & $\mathrm{Cr}$ & $\mathrm{Mn}$ & $\mathrm{Mo}$ & $\mathrm{Ni}$ & $\mathrm{P}$ & $\mathrm{Si}$ & $\mathrm{S}$ & $\mathrm{Ti}$ \\
\hline Maraging (300) & 0.087 & 0.01 & 0.007 & 9.35 & 0.06 & 0.01 & 4.67 & 18.58 & 0.004 & 0.02 & 0.002 & 0.66 \\
Elements & $\mathrm{Al}$ & $\mathrm{O}$ & $\mathrm{C}$ & $\mathrm{Co}$ & $\mathrm{N}$ & $\mathrm{Mn}$ & $\mathrm{Mo}$ & $\mathrm{Ni}$ & $\mathrm{P}$ & $\mathrm{Si}$ & $\mathrm{S}$ & $\mathrm{Ti}$ \\
Filler metal & 0.079 & 0.004 & 0.007 & 8.79 & 0.002 & 0.01 & 4.54 & 17.87 & 0.004 & 0.08 & 0.001 & 0.61 \\
\hline
\end{tabular}


Table 2: PAW parameters

\begin{tabular}{lc} 
Current & $133 \mathrm{~A}$ \\
\hline Voltage & $46 \mathrm{~V}$ \\
Welding speed & $300 \mathrm{~mm} / \mathrm{min}$ \\
Wire feed speed & $1680 \mathrm{~mm} / \mathrm{min}$ \\
Shielding gas flux (argon) & $251 / \mathrm{min}$ \\
Plasma gas flux (argon) & $3.51 / \mathrm{min}$ \\
Purge gas flux (argon) & $251 / \mathrm{min}$ \\
\hline
\end{tabular}

Table 3: Chemical etchings

\begin{tabular}{ll}
\hline Aim & Etching procedure \\
\hline Grain boundaries reveal & $-60 \% \mathrm{HNO}_{3} \mathrm{em} 40 \%$ destilated water (electrocell - 5 V) \\
Microstructural analyzes after weld & - Fry type $(40 \mathrm{~mL} \mathrm{HCl.} 5 \mathrm{~g} \mathrm{CuCl} 2.30 \mathrm{~mL}$ water. \\
& $25 \mathrm{~mL}$ ethanol $\mathrm{plus}_{20 \% \mathrm{HNO}_{3} \text { in } 80 \% \text { water }}$ \\
Microstructural analyzes after weld and heat treatment & - Nital $3 \%\left(3 \mathrm{~mL} \mathrm{HNO}_{3}\right.$ in $97 \mathrm{~mL}$ ethanol) \\
\hline
\end{tabular}
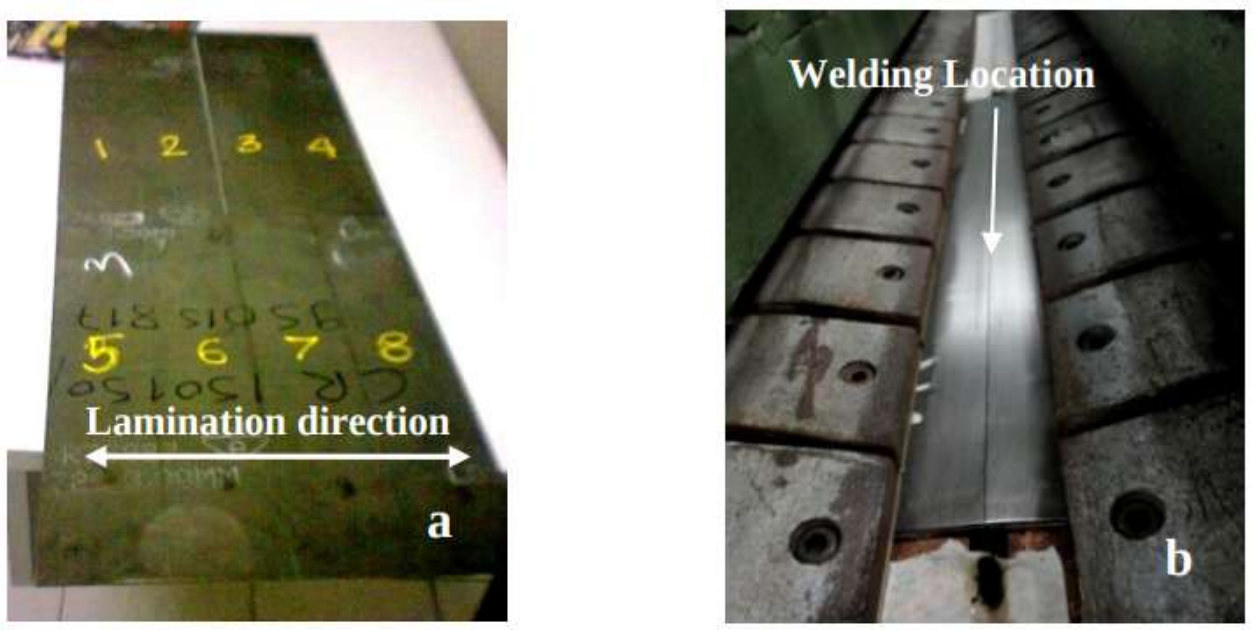

Fig. 1: (a) strips of maraging steel and (b) juxtaposed strips prepared for plasma welding
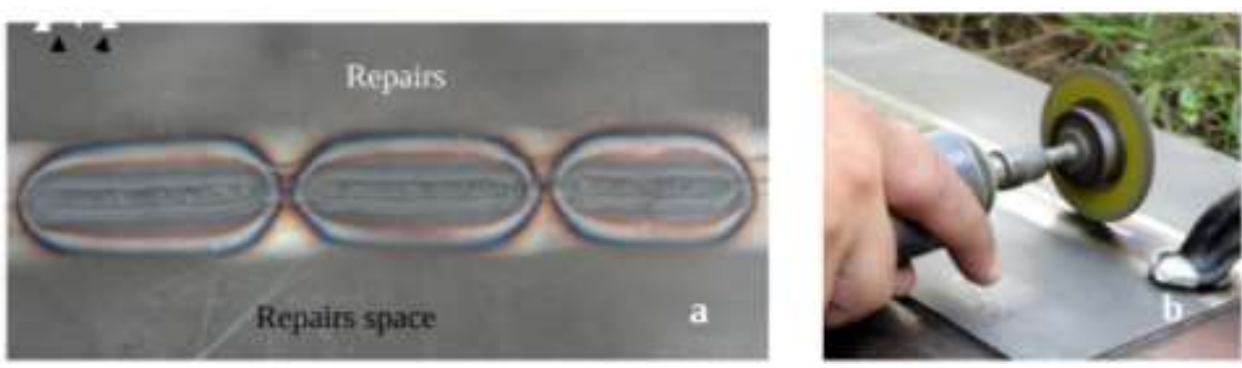

Fig. 2: (a) location of repairs and (b) opening of channel with abrasive disc for repair
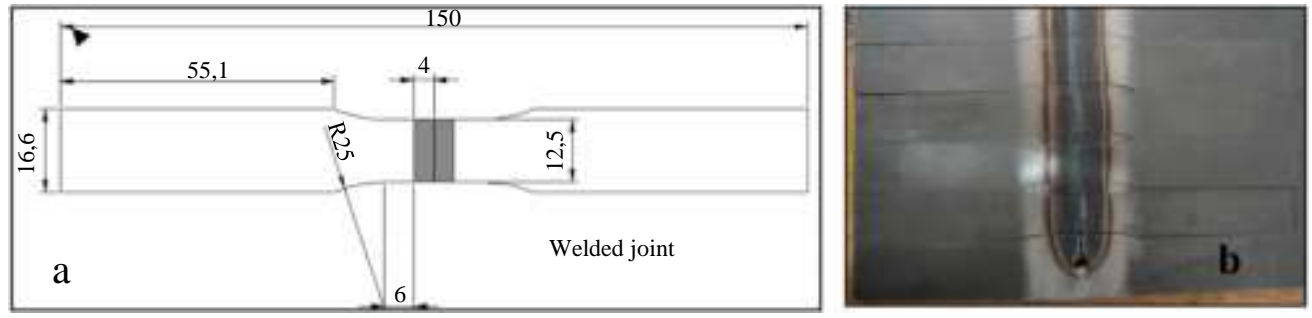

Fig. 3: (a) sample for tensile test - [36] AWS B4.0 (2007) and (b) specimen cut by wire EDM 


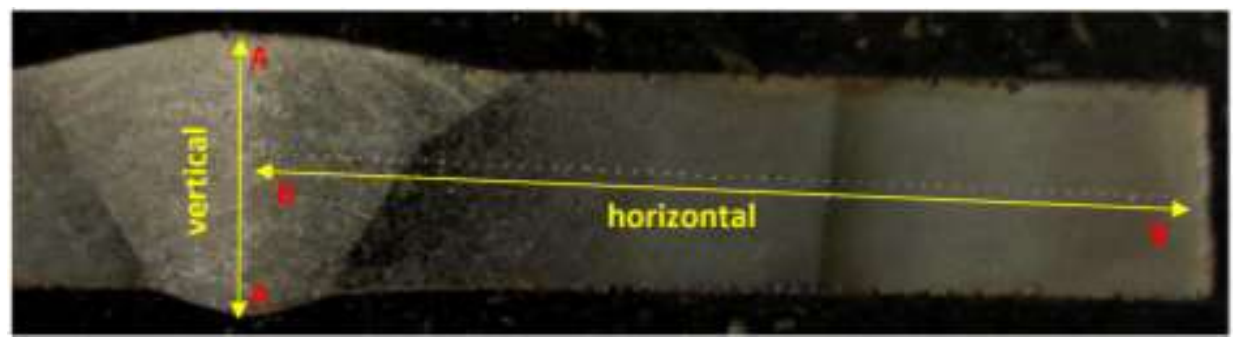

Fig. 4: Directions for microhardness measurements: A-A (vertical) and B-B (horizontal)

\section{Results and Discussion}

\section{Characteristics of Maraging Steel before Welding}

Starting Maraging 18Ni (300) steel was analyzed for its microstructure and mechanical properties before welding. repair or heat treatment processes. Table 4 shows the initial properties of the steel with respect to grain size evaluated according to the (ASTM E112-13, 2013). hardness and tensile properties. the initial condition of the steel being solubilized. The properties of the steel were also evaluated. as shown in Table 4. After receiving the thermal treatment of aging. an increase in the mechanical properties of hardness and tension is noted. with a reduction in elongation.

\section{Characteristics of Welded Steel}

\section{Microstructural Characterization after Welding}

Figure 5a shows the Fused Zone (FZ). the Heat Affected Zone (HAZ) and the Base Material (BM). In FZ there is the formation of dendritic structure due to solidification and in HAZ there is a change in the microstructure due to phase transformation or grain growth, both with changes in mechanical properties. In the BM there are no microstructural changes maintaining the original properties of the material. Images 5.b and 5.c show the FZ of the steel before and after the aging treatment, respectively. After the thermal aging treatment homogenization occurs in the microstructure and properties of the BM and HAZ regions.

In Fig. 5b it is shown how the measurements of the cord dimensions were made. The average values found were: Height (A-A). 4.0 $\pm 0.2 \mathrm{~mm}$; top width (B-B). $5.4 \pm 0.3 \mathrm{~mm}$; and root width (C-C). 2.7 $\pm 0.4 \mathrm{~mm}$. After repairs, these measures were redone.

\section{Microstructural Effects Due to Repairs}

After removing parts of the fusion zone $(70 \%$ in depth). the welds were redone, simulating 1 repair. 2 repairs and 3 repairs in the weld bead. Subsequently. the geometric and microstructural changes that these repairs caused were evaluated, because, in addition to the addition of the material, there is the effect of the repetition of thermal cycling in each repair performed. In Fig. 6 is shown the microstructures of the weld bead after repairs and the heat treatment applied. an increase in the width of the fusion zone after repairs is noted, mainly at the top of the weld. where the repair is applied.

To increase the mechanical properties it was necessary to perform the thermal treatment of aging, the images in Fig. 7 illustrate the weld bead morphology after the treatment, there are no dimensional changes due to the heat treatment.

When analyzing the weld geometry. As shown in Fig. 5b. it is noted that there is an increase in the deposition of the material after the repairs. as shown in Table 5. The increase in the dimensions of the cord (reinforcement) are not removed when used in the Brazilian rocket motor envelope. Contributing to increase the effort supported by the cylinder.

When the steel is welded, there is the formation of a dendritic region in the FZ. As shown in Fig. 8a at the interface FZ and HAZ (without repair) and $8 \mathrm{~b}$ ( 2 repairs). with enlargement of the interface marked in Fig. 7b. With black rectangle. The welds made for repair produce similar dendritic microstructures in the region. However. due to thermal cycling. close to the FZ interface, grain growth occurs. It is also noted that. Among the martensitic dendrites, there is the formation of the austenitic phase $\mathrm{Y}$ (white color), this fact occurs due to the enrichment of the elements Ni. Ti and Mo. stabilizer of this phase. of the last liquid fractions to solidify (Hall and Slunder, 1968). Fanton et al. (2014), performing laser welding of maraging 300 steels, estimated a percentage of $17 \%$ of phase $y$ in the FZ. The high temperatures and prolonged times in the treatment of aging also favor the reversion of the martensitic to austenitic phase.

A considerable increase in the initial grain size of the steel was observed in the vicinity of the FZ. Figure 9 illustrates this increase for the welded condition without repairs, it is noted that the average grain size increased about 4 times. in the vicinity of the FZ. according to ASTM. they went from a No. 9 grain to a No. 4 grain. The grains will decrease until reaching the original size of the base material. about $1 \mathrm{~mm}$ from the FZ. Venkateswara Rao et al. (2010; Fanton et al., 2014) found a similar increase in the region close to the FZ interface in maraging steels. This same behavior was observed when 
making 1.2 or 3 repairs, indicating that the thermal cycling, although producing phase transformations in the HAZ, does not lead to an increase in the grains higher than that observed due to plasma welding.

\section{Microindentation Hardness Analysis}

\section{Microhardness in the Vertical Direction}

The direction that coincides with the A-A axis in Fig. 4. From the root to the top of the weld was considered vertical. Figure 10 shows that the variations in the hardness of the weld bead, from the root to the top of the weld (vertical), before the aging treatment-HT (Fig. 10a) and after aging (Fig. 10b). The various repairs carried out did not affect the hardness in the melted area of the material producing little variation in this region.

The aging treatment increased the levels of hardness for all cases studied by about $200 \mathrm{HV}$. The graph in Fig. $10 \mathrm{~b}$ and Table 6 show the average values measured before and after the heat treatment and the variations due to the repairs carried out. After repairs and aging, there is an increase in hardness in the samples of just over $30 \mathrm{HV}$. This increase is due to the aging of the as-welded Maraging steel, which is responsible for precipitate driven pinning of dislocations.

\section{Microhardness in the Horizontal Direction}

The horizontal direction is the direction indicated by line B-B of Fig. 4. The hardness measurements were taken from the center of the Fusion Zone (FZ). passing through HAZ. and continuing towards the Base Material (BM). In Fig. 11a hardness profile is shown for each condition studied. before receiving the aging Treatment (TT).

The red reference line indicates the hardness of 349 HV. Hardness of the base material before heat treatment. It is observed that. although there is a similarity in the microhardness values in the FZ and in the transition band (ZT). there are significant changes due to the new thermal cycling due to repairs. It is noted that there is a small reduction in the hardness in the Transition Zone (ZT). a fact related to the increase in grain size, however, the hardness remains close to that of the base material (martensitic).

The higher increases in hardness values are related to the phenomenon of aging associated with the heat of the weld. In the case of unrepaired weld, the greatest effect appears at a distance between 7 and $8 \mathrm{~mm}$ from the center of the weld, where the heat has reached a temperature sufficient to cause precipitation of intermetallics, but it was not high enough for austenitization. In regions between 2 and $7 \mathrm{~mm}$ the temperatures were higher than $623^{\circ} \mathrm{C}$. austenitization temperature, according to (Reis et al., 2015). with subsequent formation of martensite in cooling with a hardness similar to that of the base material. Similar results were observed by (Sakai et al., 2016; Fanton et al., 2014) working with different types of weld.
When carrying out the first repair. it is noted that the heat displaced the precipitation region for greater distances, above $10 \mathrm{~mm}$, changing the previously aged band due to the heat imposed during the repair, sufficient to produce alteration of phases with reduction in hardness.

When the second repair is performed, the profile changes again, showing a region between 4 and $6 \mathrm{~mm}$ of hardness growth, however, not as high as the distance above $8 \mathrm{~mm}$. In this intermediate region. the temperature is such that it allows partial transformation of phases (austenite-martensite) and partial aging of the grains that have not undergone transformation. For 3 repairs, the structure is more homogeneous, with a more accentuated aging for distances greater than $11 \mathrm{~mm}$, indicating that the higher temperatures, which allow austenitization, have reached greater distances.

It is also noted in FZ some points with a drop in hardness, this fact is associated with the dendritic structure and the formation of untransformed austenite due to the increase of solute atoms in the last liquid portions to solidify, or reversed, due to reheating, a phenomenon also observed by some other authors (Reis et al., 2015; Sakai et al., 2016; de Lima et al., 2019).

Subsequently, the effect of the aging treatment on the hardness of the samples in FZ. ZT and HAZ was observed. The graphs in Fig. 12 show that aging increased the hardness. for the region of the base material and of the HAZ, to similar levels of the maraging steel without welding (red reference line - $568 \mathrm{HV}$ ) for all the studied conditions. However, it is noted that in the regions where the presence of austenite was observed in the microstructure (FZ and ZT) there is a drop in the hardness values, because the increase in hardness due to precipitation, occurs more effectively in the martensitic phase. There is also a minimum value in the transition zone because, in addition to the presence of austenite, there is also an increase in grain size in this region.

\section{Tensile Test}

The graph of Fig. 13 shows the average curves obtained in the tensile tests. of the Plasma-Welded (PAW) and aged specimens. Deformation was measured with a strain gauge placed over the FZ and HAZ. Table 7 shows the values of the limit of resistance, flow and the elongation found.

Looking at Fig. 13 and Table 7 it can be seen that the fact that steel is welded reduces the strength limit by around $7.5 \%$, compared to non-welded steel. After making repairs to the weld. this reduction remains at similar levels. the following reductions in the resistance limit were observed, according to the number of repairs: $1 \mathrm{R}-5.7 \% ; 2 \mathrm{R}-9.2 \%$ and 3R- $6.0 \%$. The yield limit levels of the repaired coupons remain high and the variation in elongation between the welded samples is small. 


\section{Fracture}

\section{Macroscopic Aspects}

Figure 14 shows the broken region of the welded specimens, with and without repairs. Broken in traction after heat treatment of solubilization and aging. Note that there is no macroscopic difference with respect to the rupture site, similarly to all conditions, with or without repairs. the fracture tends to start at the periphery of the molten zone or in the molten zone and propagates through this region. There is a coincidence of the fracture site with the positions of less hardness, located in the transition region between FZ and HAZ. due to the increase in grain size and the presence of untransformed austenite.
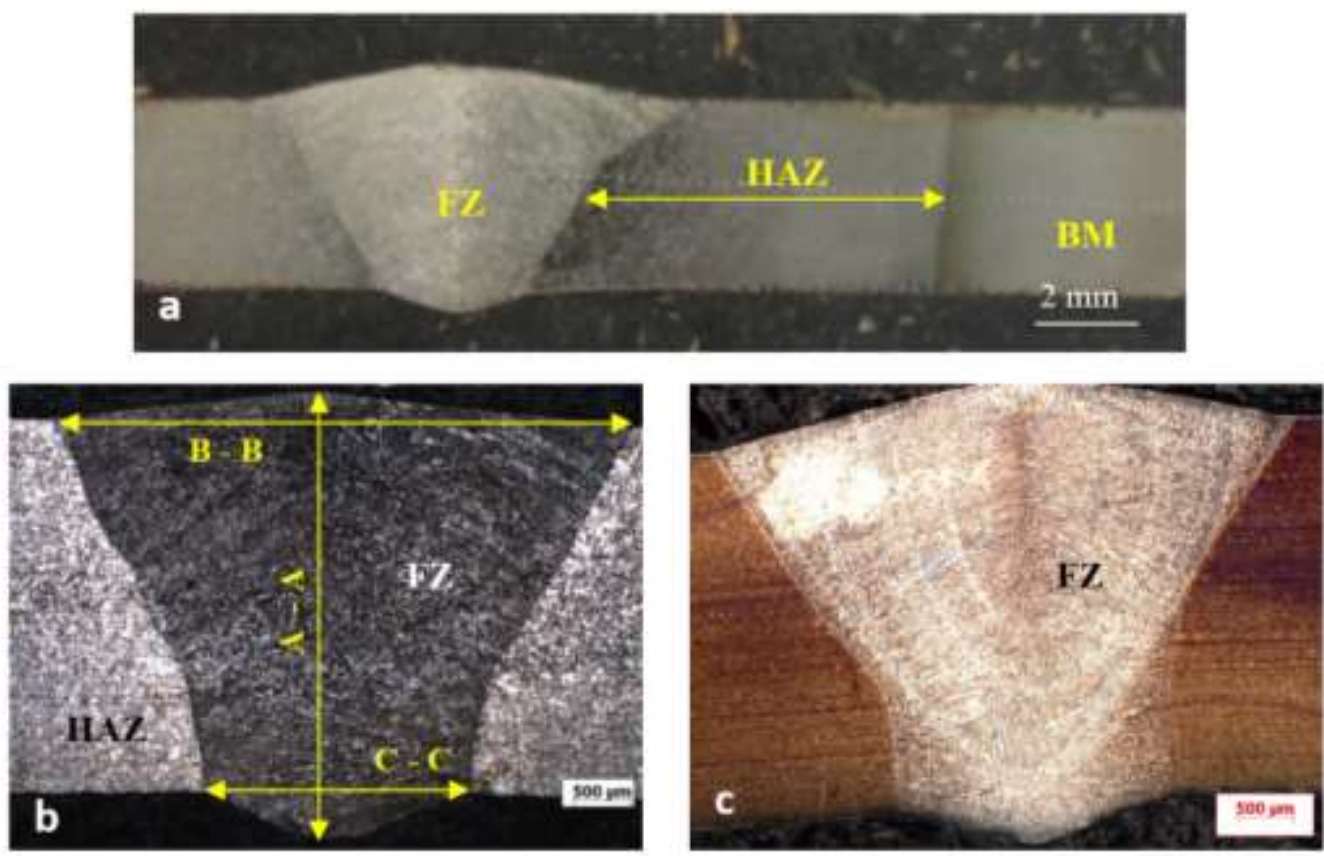

Fig. 5: Micrographs of the bead: (a) overview of the welded region (b) FZ without heat treatment and (c) FZ after heat treatment. Etch: (a) and (b) $20 \% \mathrm{HNO}_{3}$ in $80 \%$ water; (c) $3 \%$ Nital
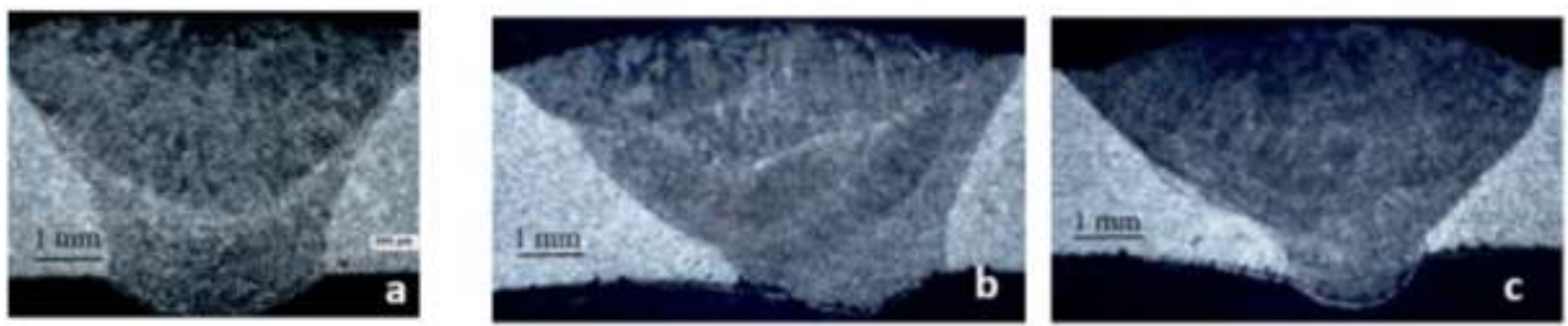

Fig. 6: Micrographs of the weld bead before heat treatment and with the application of repairs: 1 repair (a); 2 repairs (b) and 3 repairs (c). Etch: $20 \% \mathrm{HNO}_{3}$ in $80 \%$ water
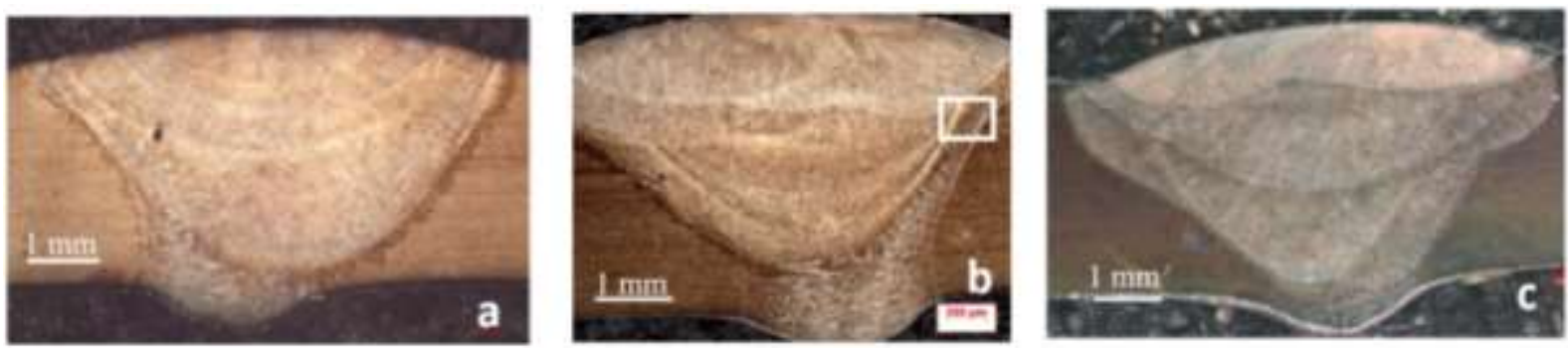

Fig. 7: Micrographs of the weld bead after heat treatment and with the application of repairs: 1 repair (a); 2 repairs (b) and 3 repairs (c). Etch: Nital 3\% 

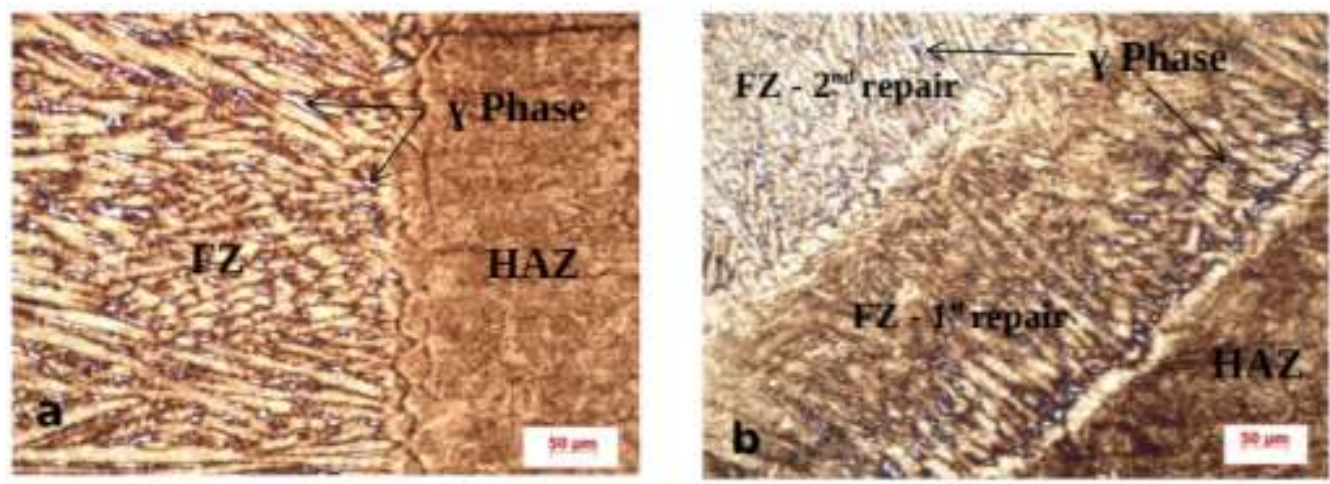

Fig. 8: Micrographs of the FZ and HAZ interface. after heat treatment: (a) Steel without repair and (b) steel with 2 repairs. Nital Etch $3 \%$

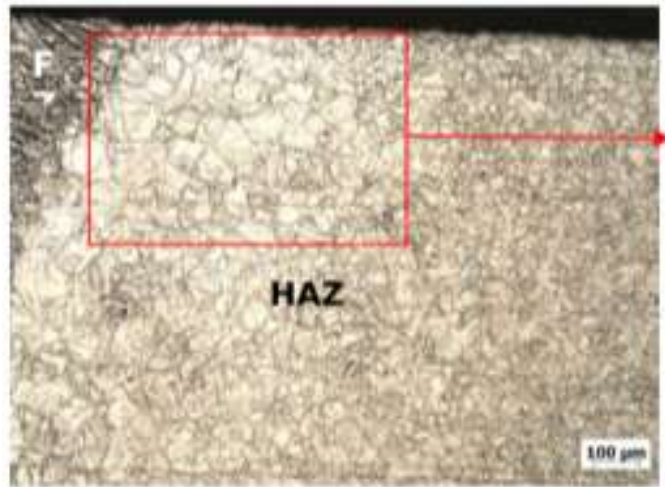

(a)

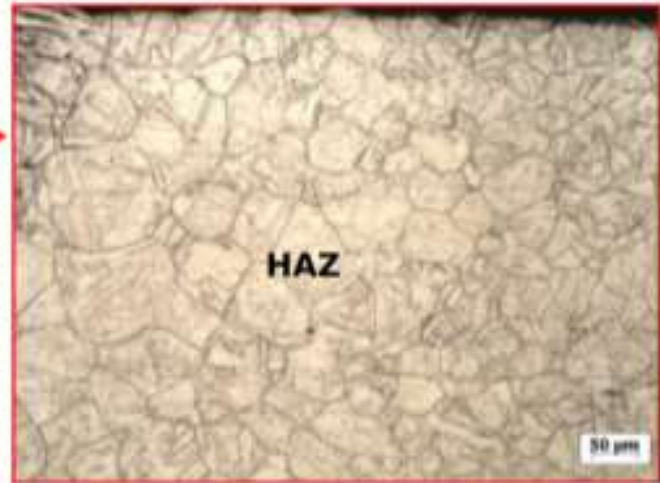

(b)

Fig. 9: Grains in the FZ-HAZ transition region: (a) showing grain size gradient and (b) showing larger grains at the interface. Etch: $60 \% \mathrm{HNO}_{3}$ in $40 \%$ distilled water. electrolytic $5 \mathrm{~V}$
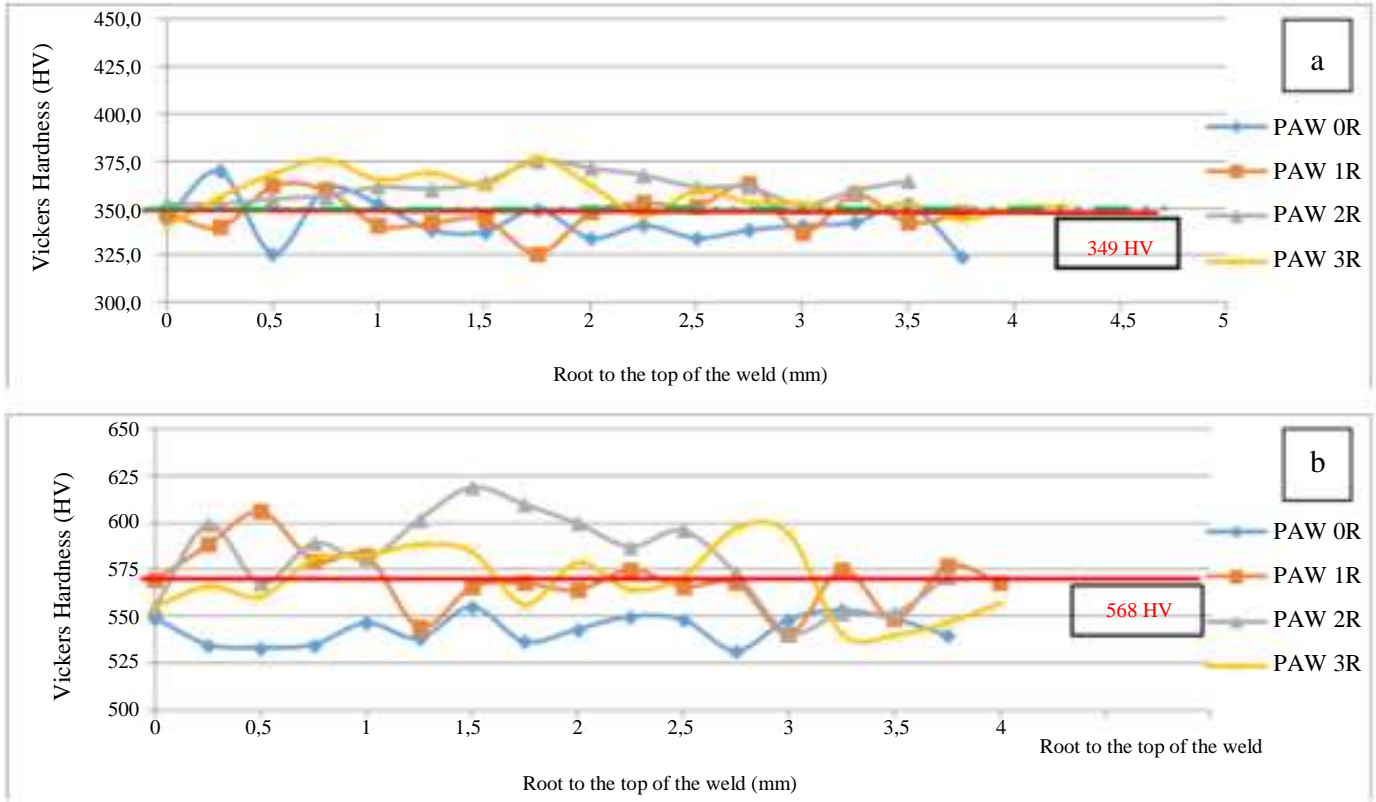

Fig. 10: Vickers Hardness (HV) in the fusion zone. vertical direction: (a) before TT and (b) after TT. (Conditions: 0R-without repair. $1 \mathrm{R}$-one repair. $2 \mathrm{R}$-two repairs and 3R-three repairs) 

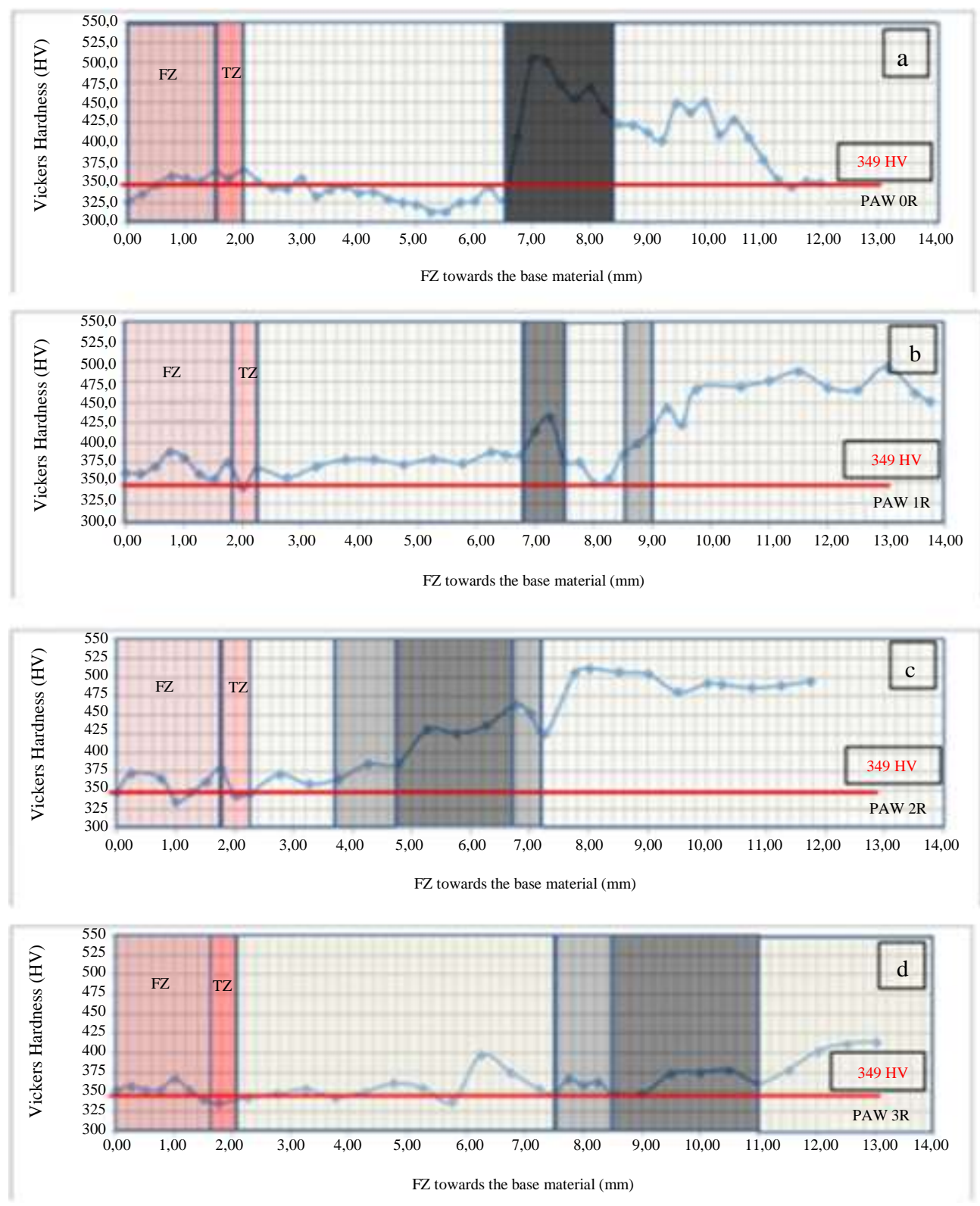

Fig. 11: Vickers Hardness (HV) in the fusion zone. horizontal direction before aging. (Conditions: (a) 0R-without repair. (b) 1R-one repair. (c) 2R-two repairs and (d) 3R-three repairs)

Although the hardness in the FZ after heat treatment may be below the value found in the transition region in some cases (Fig. 12) due to the increase in the height of the cord, a larger resistant area is offered (Table 5). However, it is a region of possible fracture propagation. The fact that there is a discontinuity between the top of the weld and the HAZ also favors the initiation of the fracture. as it creates a concentration of stresses in the region. For all samples presented in Fig. 14, the tensile strength just before the rupture was $1.8 \pm 0.1 \mathrm{GPa}$.

\section{Fracture Surface and Microscopic Aspects}

The broken surfaces were analyzed by SEM to identify the fracture micro-mechanisms. The unrepaired welded steel sample, Fig. 15b, shows an intense formation of dimples on the fracture surface with different sizes indicating that the activated micro-mechanism was the ductile fracture.

The material submitted to a repair also shows a surface full of alveoli (15d), but the macrography (15c) presents more irregularity of the surface in relation to the material without repair. 
For the case of the sample with two repairs, images in Fig. 15e and 15f, indicates that the crack has crossed the molten area and there are macroscopic irregularities indicating the presence of plastic deformations. In the image shown in Fig. 15f, it can be seen that the predominant fracture micro-mechanism was also due to dimples, similarly to the previous case. Finally, on the surface of the welded coupon with three repairs shown in Fig. 15g. there are samples of plastic deformations and in Fig. 15h dimples with reduced size are observed, both aspects related to ductile fractures.
These observations are in accordance with the elongation values observed in the tensile tests and reinforce the thesis that it is possible to weld the maraging 300 steels and apply repairs with little loss in mechanical properties and without producing fragility in the material. Both phenomena reduction in the strength limit and increase in elongation are related to the presence of austenite in the microstructure. A similar effect is observed in TRIP steels, where the presence of retained austenite is induced to increase the ductility and toughness of the steel (Lombardo et al., 2016; Anazawa et al., 2014.
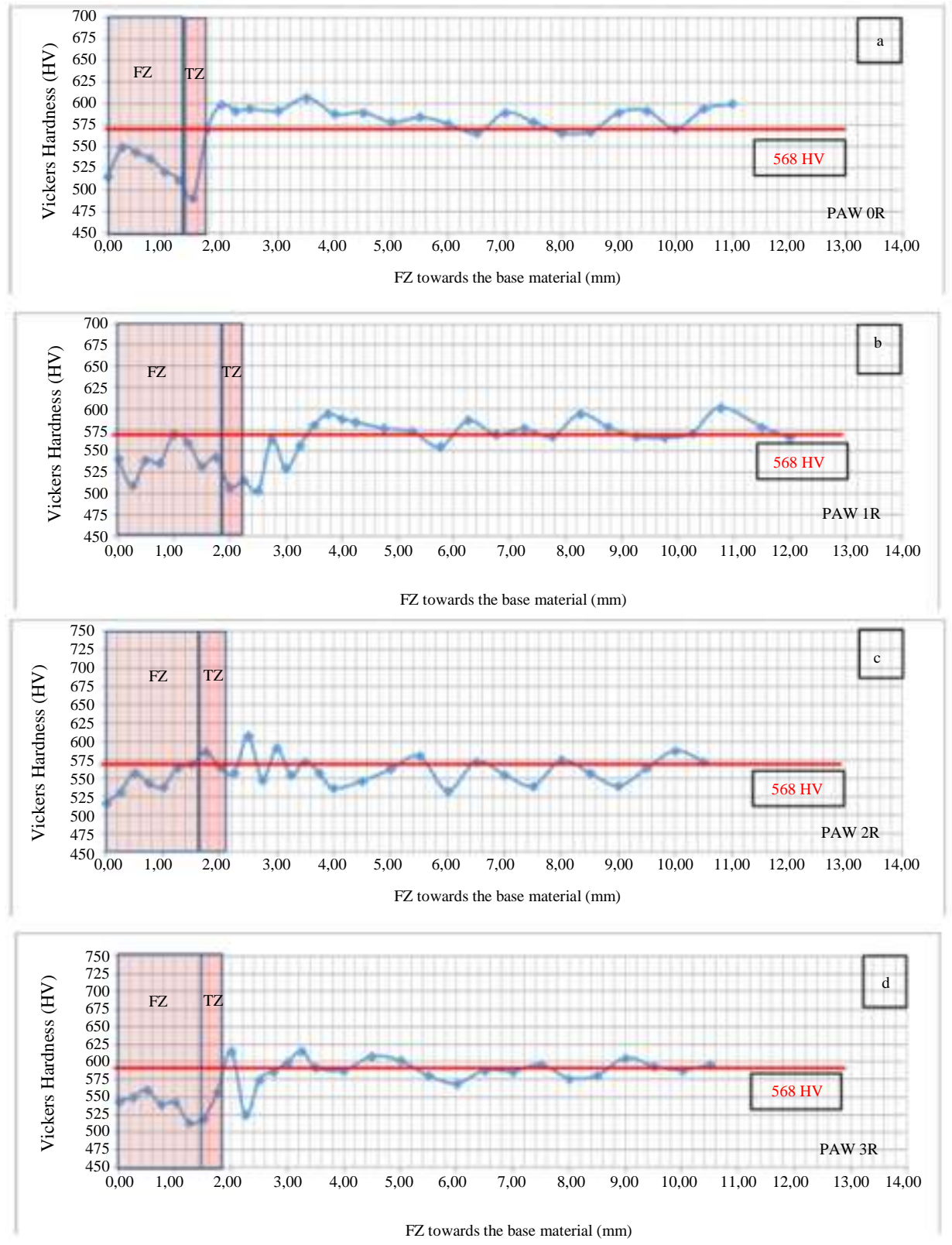

Fig. 12: Vickers hardness (HV) in the fusion zone. horizontal direction after aging. (Conditions: (a) $0 \mathrm{R}$ - without repair. (b) $1 \mathrm{R}$ - one repair. (c) $2 \mathrm{R}$ - two repairs and (d) $3 \mathrm{R}$ - three repairs) 


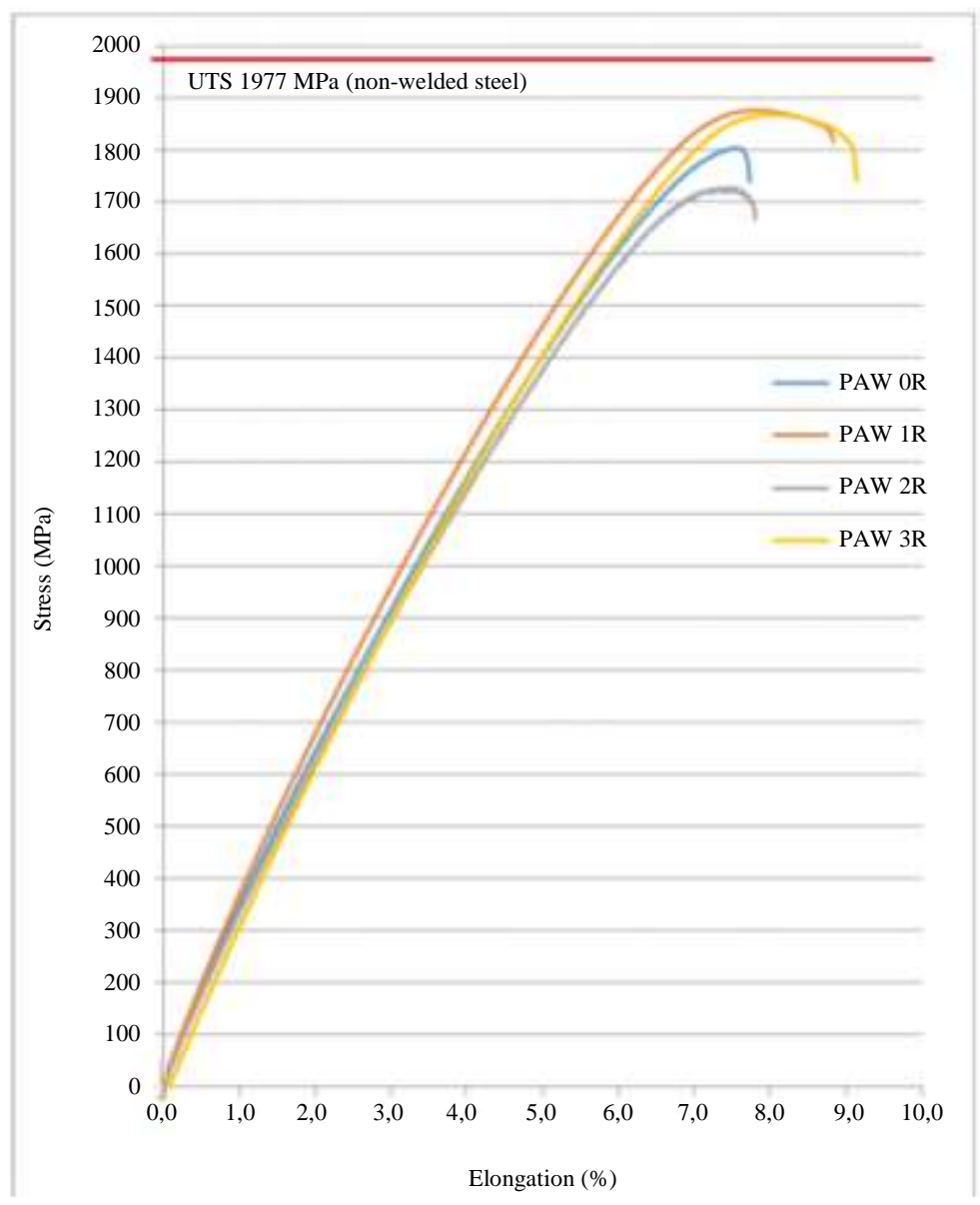

Fig. 13: Average tensile curves: Stress x Elongation
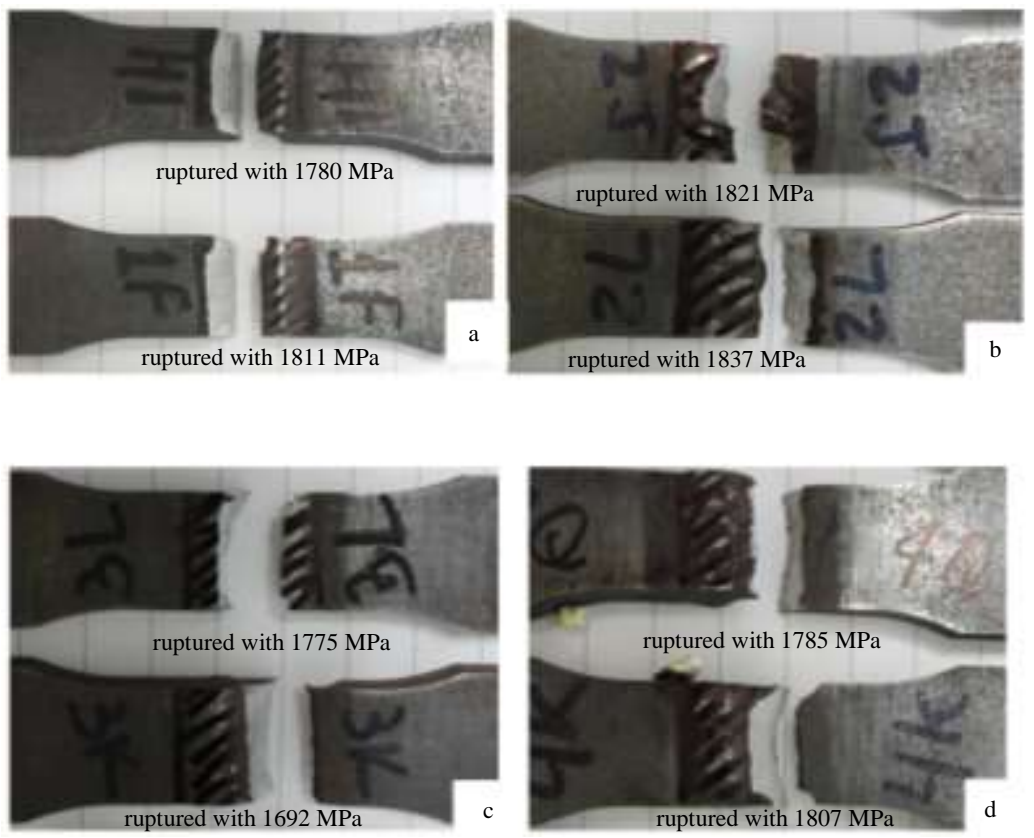

Fig. 14: Location of the rupture of the welded specimens with and without repairs; (a) without repairs. (0R); (b) one repair (1R); (c) two repairs (2R); (d) three repairs $(3 \mathrm{R})$ 

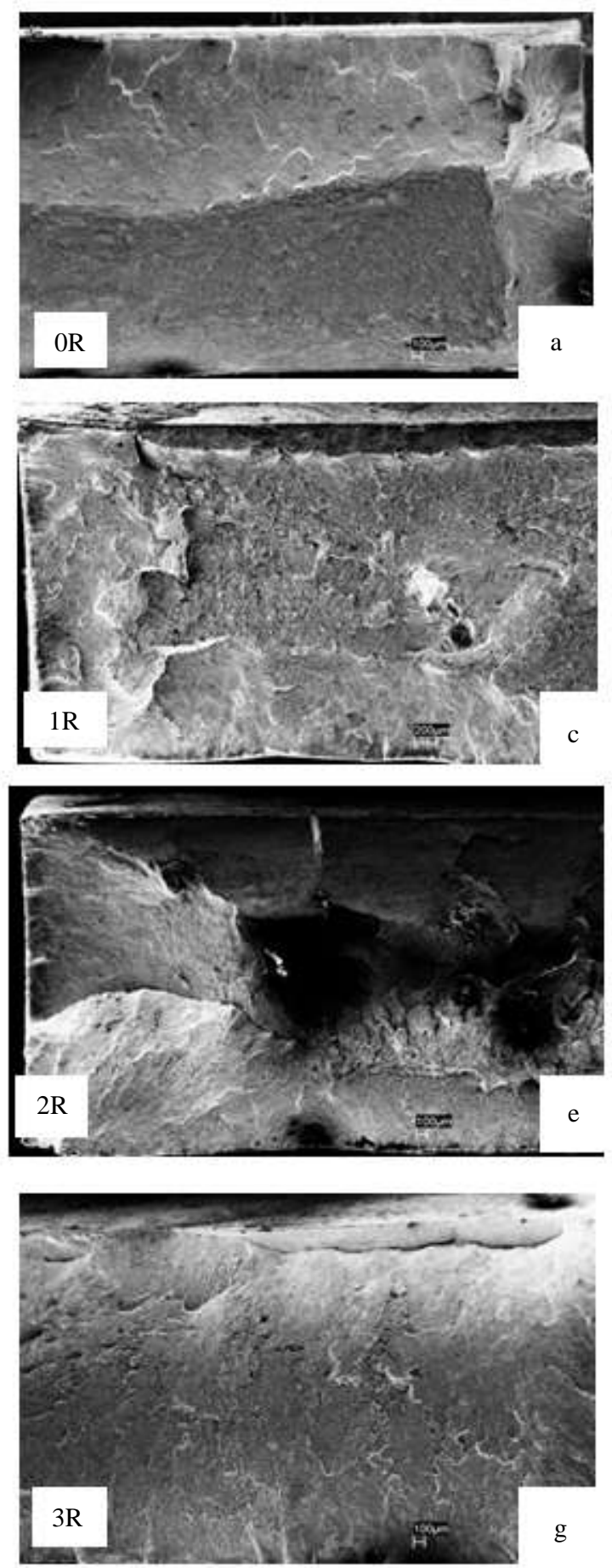
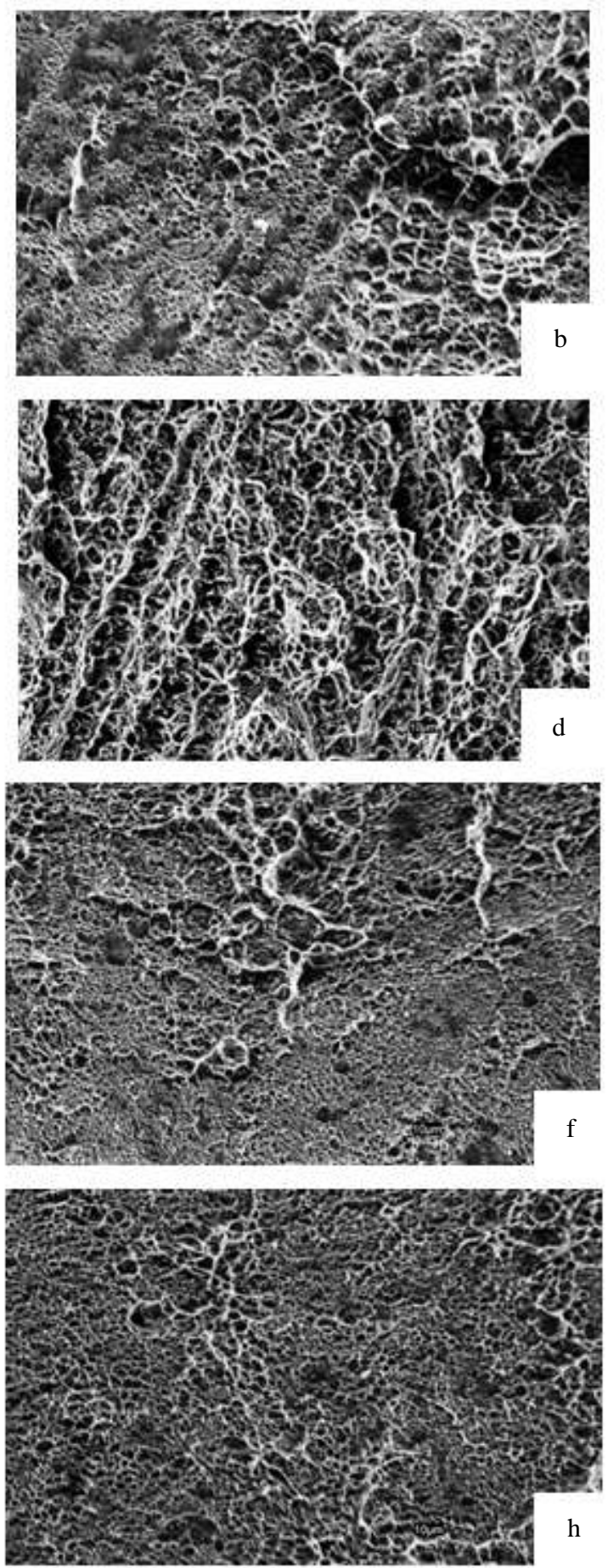

Fig. 15: SEM of the fractured surface of welded maraging steel: (a) without repair-macrography of the surface; (b) without repairsurface detail; (c) 1 repair-macrography of the surface; (d) 1 repair-surface detail; (e) 2 repairs-macrography of the surface; (f) 2 repairs-surface detail; (g) 3 repairs-surface macrography; and (h) 3 repairs-surface detail

Table 4: Initial properties of Maraging Steel. Before and after thermal aging treatment

\begin{tabular}{llllll}
\hline Maraging & ASTM & Vicker's & Tensile strength & Yield Strength & $\begin{array}{l}\text { Uniform } \\
\text { elongation }(\%)\end{array}$ \\
300 $(18 \mathrm{Ni})$ steel & Grain size & Hardness HV & HV z (MPa) & $775 \pm 17$ & $11.2 \pm 1.9$ \\
\hline Solution annealing & 9 & $332 \pm 30$ & $957 \pm 4$ & $1801 \pm 28$ & $5.3 \pm 0.4$ \\
Aged & 9 & $567 \pm 158$ & $1954 \pm 5$ & \\
\hline
\end{tabular}


Paulo Roberto Sakai et al. / Journal of Aircraft and Spacecraft Technology 2021, Volume 5: 5.20 DOI: 10.3844/jastsp.2021.5.20

Table 5: Dimensions of the weld bead-Fused Zone (FZ)

\begin{tabular}{llll} 
& Weld height $(\mathrm{A}-\mathrm{A})(\mathrm{mm})$ & Top width $(\mathrm{B}-\mathrm{B})(\mathrm{mm})$ & Root width $(\mathrm{C}-\mathrm{C})(\mathrm{mm})$ \\
\hline No repair & $4.0 \pm 0.2$ & $5.4 \pm 0.3$ & $2.7 \pm 0.4$ \\
1 repair & $4.1 \pm 0.1$ & $6.7 \pm 0.3$ & $3.1 \pm 0.2$ \\
2 repairs & $4.2 \pm 0.1$ & $6.9 \pm 0.3$ & $3.2 \pm 0.3$ \\
3 repairs & $4.4 \pm 0.3$ & $6.9 \pm 0.3$ & $3.5 \pm 0.6$ \\
\hline
\end{tabular}

Table 6: Vickers hardness values, weld bead, horizontal direction, before and after HT

Vickers Hardness-average (HV)

\begin{tabular}{lllll} 
& Number of repairs & & \\
& - & & \\
Route & No repair & 1 repair & 2 repairs & 3 repairs \\
\hline Before HT & $343 \pm 12$ & $348 \pm 10$ & $361 \pm 7$ & $341 \pm 11$ \\
After HT & $543 \pm 8$ & $570 \pm 16$ & $581 \pm 23$ & $569 \pm 18$ \\
\hline
\end{tabular}

Table 7: Tensile properties of welded steel without repair and with repairs (1R. 2R and 3R)

\begin{tabular}{llll}
\hline Condition & $\begin{array}{l}\text { Yield strength } \\
(\mathrm{MPa})\end{array}$ & $\begin{array}{l}\text { UTS } \\
(\mathrm{MPa})\end{array}$ & $\begin{array}{l}\text { Elongation } \\
(\%)\end{array}$ \\
\hline OR & $1676 \pm 28$ & $1829 \pm 34$ & $7.6 \pm 0.8$ \\
1R & $1645 \pm 18$ & $1864 \pm 24$ & $7.8 \pm 1.1$ \\
2R & $1765 \pm 31$ & $1795 \pm 51$ & $7.5 \pm 0.9$ \\
3R & $1705 \pm 29$ & $1858 \pm 32$ & $8.0 \pm 1.2$ \\
\hline
\end{tabular}

\section{Conclusion}

The welds carried out by the plasma process allowed a good union in Maraging 18 (Ni) steel. The performance of repairs (one. two and three repairs) showed that. as the number of repairs increases, there is an increase in the dimensions of the Fused area (FZ) and the Heat Affected area (HAZ), without prejudice to the mechanical properties.

Before the thermal treatment of aging it is noted that the hardness measurements of the FZ. ZT (Transition Zone FZ-HAZ) show a drop, associated with the presence of austenite in the microstructure. In the ZT. in addition to the austenite phase, grain growth was observed, which went from ASTM 9 to 4. In HAZ, there are certain regions where there was an increase in hardness due to the effect of aging, these bands of greater hardness moved for FZ, as the number of repairs increased.

After the heat treatment of aging, the hardness values of the steel increased. At HAZ, even after the repairs were applied. the values reached the same levels as the aged base material. However, although the hardness of FZ and ZT increased, they still showed hardness values below the expected value for the aged base material, an effect related to the presence of austenite in the region.

The mean values of the limit of tensile strength obtained varied from a lower value of $1795 \mathrm{MPa}$. in the sample with 2 repairs, to the highest value of $1864 \mathrm{MPa}$ sample with 1 repair. These values, considering the standard deviation of about $30 \mathrm{MPa}$, are similar to the average value observed in welded and aged steel without repairs: $1829 \mathrm{MPa}$. Comparing these values with the resistance limit of the base material aged before welding (1977 MPa), it is noted that the loss of resistance is less than $10 \%$.

The analysis of the steel fracture surface after welding, repairs and aging, showed that the specimens broke in the region between FZ and ZT. This fact is associated with the presence of austenite in these regions and the phenomenon of grain growth in the ZT interface (FZ-HAZ). As a rule, the fracture started in the region close to the melting line and spread into the weld bead. Nevertheless, the fracture micromechanisms were ductile, with the formation of dimples across the fracture surface indicating that. for all welding conditions, without repair or with up to 3 repairs, no fragile fracture occurred. A factor that indicates viability plasma welding on maraging steel and the possibility of carrying out repairs, if necessary, without loss of strength or ductility.

\section{Acknowledgement}

The authors thank Institute for Advanced Studies-IEAv, São Paulo Research Foundation (FAPES) and National Council for Scientific and Technological Development $(\mathrm{CNPq})$ for the support received to the research.

\section{Author's Contributions}

Paulo Roberto Sakai: Realized the microstructural and mechanical characterization.

Deivid Ferreira da Silva: Realized the welding experiments.

Milton Sérgio Fernandes de Lima: Realized the revision of the manuscript and contributed to the discussions.

Rafael Humberto Mota de Siqueira: Complicated and analysed mechanical results.

Antonio Jorge Abdalla: Organized the experimental work. 


\section{Ethics}

This article is original and contains unpublished material. The corresponding author confirms that all of the other authors have read and approved the manuscript and no ethical issues involved

\section{References}

Ahmed, B., Tariq, F., Naz, N., \& Baloch, R. A. (2012). How Multiple Weld Repairs Impact Maraging Steel. Welding Journal, 91(10), 38-46.

AMS 2759/3E. (2008). Heat Treatment PrecipitationHardening Corrosion-Resistant and Maraging Steel parts. USA. Aerospace Material Specification. https://webstore.ansi.org/standards/sae/saeams27593 e2008ams 2759

AMS 6463D. (2009) Wire. Steel Welding 18.5Ni - 8.5Co 5.2Mo - 0.72Ti - 0.10Al (Marage 300) Vacuum Melted. Environment Controlled Packaging. USA. Aerospace Material Specifications. https://webstore.ansi.org/standards/sae/saeams6463d20 09ams6463d

AMS 6514G. (2010). Steel. Maraging. Bars. Forgings. Tubing. and Rings $18.5 \mathrm{Ni}-9.0 \mathrm{Co}-4.9 \mathrm{Mo}-0.65 \mathrm{Ti}$ 0.10Al Consumable Electrode Vacuum Melted. Annealed (Composition similar to UNS K93120). USA. Aerospace Material Specifications. https://webstore.ansi.org/standards/sae/saeams6514g 2010ams6514g

AMS 6521C (1991). Steel Sheet. Strip. and Plate. Maraging. 18.5Ni - 9.0Co - 4.9Mo - 0.65Ti - 0.10Al. Consumable Electrode Melted. Solution Heat Treated. USA. Aerospace Material Specifications. https://www.specificsteel.com/Marage-300-31-4442

Anazawa, RM, Abdalla, AJ, Hashimoto, TM, \& Pereira, MS (2014). Comparative study of mechanical properties in 4340 and $300 \mathrm{M}$ steels subjected to isothermal and intercritical heat treatments. Brazilian Journal of Vacuum Applications, $31 \quad$ (1-2), 32-37. http://www.sbvacuo.org.br/rbav/index.php/rbav/article/ view/918

ASM. (2019). Handbook online. ASM desk editions. Ultrahigh-Strength Steels. Disponível em http://products.asminternational.org/hbk/index.jsp

ASTM E112-13. (2013). Standard Test Methods for Determining Average Grain Size. USA. American Society For Testing And Materials.

AWS B4.0. (2007). Standard Methods for Mechanical Testing of Welds. USA. American Welding Society. https://pubs.aws.org/Download_PDFS/B4.02007PV.pdf

Blondeau, R. (2008). Metallurgy and Mechanics of Welding: Processes and Industrial Applications. London: ISTE Ltd. and John Wiley \& Sons.
Bruhn, E. F. (1967). Analysis and design of missile structures. https://ci.nii.ac.jp/naid/10003983102/

Chakravarthi, K. V. A., Koundinya, N. T. B. N., Murty, S. N., \& Rao, B. N. (2017). Microstructural evolution and constitutive relationship of M350 grade maraging steel during hot deformation. Journal of Materials Engineering and Performance, 26(3), 1174-1185. https://link.springer.com/article/10.1007\%2Fs11665017-2539-4

de Lima, M. S. F., de Mota Siqueira, R. H., de Carvalho, S. M., \& Abdalla, A. J. (2019). Hardening effects of in-situ aging for a laser welded maraging steel.

Dos Reis, A. G., Reis, D. A. P., Abdalla, A. J., \& Otubo, J. (2015). High-temperature creep resistance and effects on the austenite reversion and precipitation of $18 \mathrm{Ni}$ (300) maraging steel. Materials Characterization, $\quad$ 107, 350-357. https://www.sciencedirect.com/science/article/abs/pi i/S1044580315002971

ESA. (2004). European Space Agency. ECSS-Q-70-71A: Data for selection of space materials and processes. Rev. 1. 18. http://www.esmat.esa.int/ecss-q-7071a.pdf

Fanton, L., Abdalla, A. J., \& Lima, M. S. F. (2014). Heat treatment and ybfiber laser welding of a maraging steel. Welding Journal, 93, 362-368. https://www.researchgate.net/publication/28695638 5_Heat_Treatment_and_Yb-

Fiber_Laser_Welding_of_a_Maraging_Steel

Galindo-Nava, E. I., Rainforth, W. M., \& Rivera-Díaz-delCastillo, P. E. J. (2016). Predicting microstructure and strength of maraging steels: Elemental Optimisation. Acta Materialia, 117, 270-285. https://www.sciencedirect.com/science/article/abs/pii/S 135964541630516X

Hall, A. M., \& Slunder, C. J. (1968). The metallurgy, behavior and application of the 18-percent nickel maraging steels. Battelle Memorial Inst Columbus $\mathrm{OH}$ Columbus Labs. https://apps.dtic.mil/sti/citations/ADA382105

He, B., Tian, X. J., Cheng, X., Li, J., \& Wang, H. M. (2017). Effect of weld repair on microstructure and mechanical properties of laser additive manufactured Ti-55511 alloy. Materials \& Design, 119, 437-445. https://www.sciencedirect.com/science/article/abs/pii/S 0264127517300734

Kanne Jr, W. R., Louthan Jr, M. R., Rankin, D. T., \& Tosten, M. H. (1999). Weld repair of irradiated materials. Materials Characterization, 43(2-3), 203-214. https://www.sciencedirect.com/science/article/abs/pii/S 1044580399000327 
Lombardo, S., Nascimento Ferreira, R., de Souza Santos, L. A., de Jesus Silva, J. W., Bagio Scheid, V. H., \& Abdalla, A. J. (2016). Microstructural characterization of joints of maraging 300 steel welded by Laser and subjected to plasma nitriding treatment. In Materials Science Forum (Vol. 869, pp. 479-483). Trans Tech Publications Ltd. https://www.scientific.net/MSF.869.479

Marcisz, J., Adamczyk, M., \& Garbarz, B. (2017). Optimisation of mechanical properties of $18 \% \mathrm{Ni350}$ grade maraging steel using novel heat treatment. Archives of Metallurgy and Materials, 62. http://yadda.icm.edu.pl/yadda/element/bwmeta1.ele ment.baztech-5ac50491-c418-4dc4-b2e13918f2a0910f

Matsuo, H., \& Kawaguchi, J. I. (1995). M-V Launch Vehicle. Acta Astronautica Vol. 35. Suppl.. pp. 597-603. Elsevier Science Ltd.. Printed in Great Britain. https://doi.org/10.1016/00945765(94)00227-D

Pardal, J. M. (2012). Aço Maraging classe 300: Propriedades mecânicas e magnéticas em diversas condições de tratamento térmico. São Paulo: Ed gard Boucher.

Pardal, J. M., Tavares, S. S. M., Fonseca, M. C., Abreu, H. F. G., \& Silva, J. J. M. (2006). Study of the austenite quantification by X-ray diffraction in the $18 \mathrm{Ni}-\mathrm{Co}-\mathrm{Mo}-\mathrm{Ti}$ maraging 300 steel. Journal of Materials Science, 41(8), 2301-2307. https://link.springer.com/article/10.1007/s10853006-7170-y

Poinke, L. J., \& Garland, K. C. (1973). Evaluation of shuttle solid rocket booster case materials. Contractor report, NASA, Marshall Space Flight Center, Ala.

Rajan, K. M., \& Narasimhan, K. (2002). An approach to selection of material and manufacturing processes for rocket motor cases using weighted performance index. Journal of Materials Engineering and Performance, 11(4), 444-449. https://link.springer.com/article/10.1361/105994902 770343980

Reimann, M., Goebel, J., \& dos Santos, J. F. (2017). Microstructure and mechanical properties of keyhole repair welds in AA 7075-T651 using refill friction stir spot welding. Materials \& Design, 132, 283-294. https://www.sciencedirect.com/science/article/abs/pi i/S0264127517306743

Reis, A. G., Reis, D. A. P., Abdalla, A. J., Couto, A. A., \& Otubo, J. (2016). An In Situ High-Temperature X-Ray Diffraction Study of Phase Transformations in Maraging 300 Steel. In Defect and Diffusion Forum (Vol. 371, pp. 73-77). Trans Tech Publications Ltd. https://www.scientific.net/DDF.371.73
Reis, A. G., Reis, D. A. P., Abdalla, A. J., Otubo, J., \& Sandim, H. R. Z. (2015, October). A dilatometric study of the continuous heating transformations in maraging 300 steel. In IOP Conference Series: Materials Science and Engineering (Vol. 97, No. 1, p. 012006). IOP Publishing. https://iopscience.iop.org/article/10.1088/1757899X/97/1/012006/meta

Sakai, P. R., da Silva, D. F., Lombardo, S., \& Abdalla, A. J. (2016). Comparison of Mechanical and Microstructural Characteristics in Maraging 300 Steel Welded by PAW and GTAW processes submitted to repair. In Advanced Materials Research (Vol. 1135, pp. 255-264). Trans Tech Publications Ltd. https://www.scientific.net/AMR.1135.255

Sakai, P. R., Lima, M. S. F., Fanton, L., Gomes, C. V., Lombardo, S., Silva, D. F., \& Abdalla, A. J. (2015a). Comparison of mechanical and microstructural characteristics in maraging 300 steel welded by three different processes: LASER, PLASMA and TIG. Procedia Engineering, 114, 291-297. https://www.sciencedirect.com/science/article/pii/S1 877705815017105

Sakai, P. R. (2015b). Characterization of welded joints in paw and gtaw of thin sheets in maraging steel 300 subjected to several repairs. https://repositorio.unesp.br/handle/11449/132887

Schmidt, M., \& Rohrbach, K. (1991). Heat treating of maraging steels. ASM International, ASM Handbook., 4, 219-228.

Sinha, P. P., Arumugham, S., \& Nagarajan, K. V. (1993). Influence of repair welding of aged $18 \mathrm{Ni} 250$ maraging steel weldments on tensile and fracture properties. WELDING JOURNAL-NEW YORK-, 72, 391-s. http://files.aws.org/wj/supplement/WJ_1993_08_s391. pdf

Sun, K., Peng, W., Wei, B., Yang, L., \& Fang, L. (2020). Friction and wear characteristics of $18 \mathrm{Ni}$ (300) maraging steel under high-speed dry sliding conditions. Materials, 13(7), 1485. https://www.mdpi.com/1996-1944/13/7/1485

Suresh, B. N. (2008). History of Indian launchers. Acta Astronautica, 63(1-4), 428-434. https://www.sciencedirect.com/science/article/abs/pi i/S0094576507003712

Teng, J., Wang, D., Wang, Z., Zhang, X., Li, Y., Cao, J., ... \& Yang, F. (2017). Repair of arc welded DH36 joint by underwater friction stitch welding. Materials \& Design, 118, 266-278. https://www.sciencedirect.com/science/article/abs/pi i/S0264127517300175 
Vasudevan, V. K., Kim, S. J., \& Wayman, C. M. (1990). Precipitation reactions and strengthening behavior in $18 \mathrm{Wt}$ Pct nickel maraging steels. Metallurgical Transactions A, 21(10), 2655-2668. https://link.springer.com/article/10.1007\%2FBF0 2646061
Venkateswara Rao, V., Madhusudhan Reddy, G., \& Sitarama Raju, A. V. (2010). Influence of postweld heat treatments on microstructure and mechanical properties of gas tungsten arc maraging steel weldments. Materials Science and Technology, 26(12), 1459-1468. https://www.tandfonline.com/doi/abs/10.1179/174 328409X410854 